\title{
Objeto de estudo ou matéria estrangeira? Contribuições da análise filosófica de Yves Schwartz para os estudos sobre o trabalho
}

\author{
Tatiana Ramminger ${ }^{1}$ \\ Universidade Federal Fluminense
}

O artigo traz as contribuições do filósofo Yves Schwartz, a partir de sua análise dos estudos filosóficos sobre o trabalho, para a reflexão quanto à importância do saber dos trabalhadores para a compreensão do trabalho contemporâneo. Inicia com a apresentação sucinta de alguns autores e ideias privilegiadas quando se toma o trabalho e suas metamorfoses como objeto de estudo na atualidade. Em um segundo momento, apresenta um texto de Schwartz, no qual ele identifica uma linhagem, na tradição filosófica ocidental, que, mais que objeto de estudo, considerou o trabalho como "matéria estrangeira", colocando em destaque o saber dos trabalhadores e a necessária posição de humildade dos especialistas e pesquisadores diante dos mundos do trabalho.

Palavras-chave: Trabalho, Sociologia, Filosofia, Ergologia.

Object of study or foreign matter? Contributions of philosophical analysis of Yves Schwartz for studies on the work

The paper features the contributions of the philosopher Yves Schwartz, from his analysis of philosophical studies on the work for reflection on the importance of the knowledge workers to understand the contemporary work. Start with the summary presentation of some authors and ideas favored when taking work and its metamorphoses as the object of study today. In a second step, has a Schwartz paper in which he identified a lineage in the Western philosophical tradition, more than object of study, considered the work as "foreign matter", emphasizing the knowledge of workers and the necessary position of humility experts and researchers face the worlds of labour.

Keywords: Work, Sociology, Philosophy, Ergology.

"Eu não definirei alguma coisa por sua essência, o que ela é. Eu a definirei por esta definição bárbara, o seu possest: o que ela pode. Literalmente: o que ela pode em ato" (Deleuze).

$\mathrm{O}$ presente artigo é uma reflexão sobre os estudos filosóficos a respeito do trabalho, guiada pelo filósofo francês Yves Schwartz. Inicia com a apresentação sucinta dos autores e ideias que costumam ser discutidas, quando se toma o trabalho como objeto de estudo na atualidade, inclusive no campo da psicologia social do trabalho. Em um segundo momento, apresenta um texto recentemente publicado de Schwartz, no qual o autor identifica, na tradição filosófica ocidental, uma linhagem que privilegiou o trabalho como "matéria estrangeira", apontando a necessária posição de humildade e aprendizagem dos especialistas e pesquisadores diante dos mundos do trabalho e do saber dos trabalhadores.

1 Doutora em Saúde Pública pela Escola Nacional de Saúde Pública da Fundação Oswaldo Cruz. Professora do Departamento de Psicologia, Escola de Ciências Humanas e Sociais, Polo Universitário de Volta Redonda, Universidade Federal Fluminense. 


\section{Considerações da sociologia: as metamorfoses do trabalho}

Neste primeiro momento, apresentamos brevemente algumas discussões do campo da sociologia a respeito do trabalho e de suas metamorfoses. Embora a sociologia tenda a fazer uma história linear de uma categoria universal - o Trabalho, consideramos importante tanto conhecer os estudos clássicos sobre o trabalho como contextualizar os debates atuais, preocupados em marcar mudanças no entendimento do que é trabalho, sobretudo no que diz respeito à sua função como categoria central de análise e de coesão social das sociedades modernas.

Arendt (1995) e Meda (1999) consideram que na matriz grega da sociedade ocidental sequer havia uma palavra designando trabalho; talvez, o que mais se aproxime do conceito moderno de trabalho seja a atividade que cabia aos escravos - sofrimento e infortúnio daqueles que haviam perdido sua liberdade. Tampouco o trabalho era o fundamento do laço social, mas sim as atividades éticas e políticas que estavam associadas à função do cidadão livre. A divisão hierárquica e social do trabalho era clara e dizia respeito não à atividade em si, mas à dependência de outrem. A vida livre deveria estar além das necessidades básicas, e o trabalho tinha de ter um sentido para a pessoa que o realizasse, um valor para ela. Se fosse realizado por um valor outro - como para a sobrevivência - ou em função de outro - como no caso do escravo - era considerado indigno (Nardi, 2006).

A sociedade feudal, assim como a grega, estabelecia uma hierarquia rígida com relação ao trabalho. Basicamente, essa hierarquia era dividida entre o clero, o senhor feudal e os servos. Sob influência do cristianismo, o trabalho também não era valorizado, estando ligado, como registrado na Bíblia, como punição pelo pecado original, sendo o homem condenado a ganhar "o pão com o suor do seu rosto" (Gn 3:19). As duas origens latinas da palavra "trabalho" remetem a essa relação entre trabalho e castigo: "tripalium" (para alguns autores, instrumento agrícola para processar cereais; para outros, triângulo colocado ao redor do pescoço do boi para guiá-lo) e "trepalium" (instrumento de tortura da idade média) trazem consigo a ideia de sofrimento.

Já a palavra inglesa "work" remete a werg-on, que quer dizer "fazer" (to do, to act) (Nardi, 2006). Essa diferença etimológica permite-nos explorar uma ruptura fundamental em relação ao sentido do trabalho, quando a reforma protestante the atribuiu um valor positivo(Weber, 2004 [1904]), consolidando o trabalho como categoria associada à criação de riqueza.

A "sociedade do trabalho", aquela em que o trabalho transforma-se na própria essência do homem, só foi possível com um processo vertiginoso de mudanças na ordem social que, de tão radicais, chegaram a demarcar um novo período na história da humanidade: a Modernidade. A morte de Deus na filosofia (Kant), bem como de seus representantes terrenos (a nobreza decapitada na Revolução Francesa), a ascensão da burguesia, a criação dos estadosnação e a consolidação da Revolução Industrial corroboraram para aquilo que alguns autores identificam como a "invenção do trabalho" (Meda, 1999; Gorz, 2003).

Foi uma revolução, uma subversão do modo de vida, dos valores, das relações sociais e das relações com a natureza, uma invenção, no sentido pleno do termo, de algo que jamais existira antes. A atividade produtiva desfazia-se de seu sentido original, de suas motivações e de seu objeto para tornar-se simples meio de ganhar um salário. Deixava de fazer parte da vida para tornar-se o meio de "ganhar a vida" (Gorz, 2003, p. 30). 
Já no século XX, as críticas ao modo capitalista e liberal ${ }^{2}$ de produção, somadas à força da teoria marxista, à organização dos sindicatos dos trabalhadores, entre outros tensionamentos, provocaram novas mudanças. $\mathrm{O}$ mundo se dividiu basicamente entre países capitalistas e socialistas ${ }^{3}$. Essa reorganização possibilitou, inclusive, poder de barganha à luta dos trabalhadores nos países capitalistas, determinando outra relação na tríade Estado-CapitalTrabalho, em um pacto conhecido como "Estado de Bem-Estar Social" (welfare state). As relações de trabalho assumem a forma contratual do emprego assalariado, regulamentado e estável, integrado a um sistema de proteção pelo Estado. Foi o período mundialmente conhecido como "Trinta Gloriosos" - anos de estabilidade (e de garantias sociais) do pós-guerra (1945-1975).

É óbvio que esse processo não foi homogêneo; ao contrário, deu-se de forma completamente diferente, se considerarmos a Europa, os Estados Unidos ou o "Terceiro Mundo" . No caso do Brasil, por exemplo, a genealogia do trabalho construída dá pistas, mas está longe de analisar em profundidade certas especificidades da nossa realidade, tais como a influência do regime escravocrata ou da (pseudo) revolução industrial tardia nas relações de trabalho brasileiras. Da mesma forma, o welfare state, amplamente discutido por autores estrangeiros, não se consolidou no continente sul-americano. No entanto, mesmo que de forma precária, também desenvolvemos no Brasil a cultura do trabalho como modo de integração e coesão social, com o emprego (a "carteira assinada") garantindo alguns direitos aos trabalhadores, como salário mínimo, assistência à saúde e previdência social (Nardi, 2006).

Em relação à base técnica da organização do trabalho, o período que compreende praticamente todo o século XX é caracterizado pelo modelo taylorista-fordista. Taylor propôs a administração "científica" do trabalho, consolidando a separação entre planejamento e execução na atividade de trabalho, enquanto Ford levou ao máximo essa separação, com as linhas de montagem, assim como compreendeu que os operários, para além de trabalhadores, deveriam ser, também, consumidores (Antunes, 2000).

Para os sociólogos, no entanto, nos últimos trinta anos, uma ruptura histórica se anuncia, ameaçando o papel integrador do trabalho. Essa ameaça está ligada, essencialmente, à desregulamentação das relações de trabalho, como resultado do processo conhecido como reestruturação produtiva. Para Antunes (2000), o longo período de acumulação de capital começou a dar sinais de cansaço, a partir dos anos 1970, com o esgotamento do padrão de acumulação taylorista-fordista.

Como resposta a sua própria crise, iniciou-se um processo de reorganização do capital e de seu sistema ideológico e político de dominação, cujos contornos mais evidentes foram o advento do neoliberalismo, com a privatização do Estado, a desregulamentação dos direitos do trabalho e a desmontagem do setor produtivo estatal (...); a isso se seguiu também um intenso processo de reestruturação da produção e do trabalho (Antunes, 2000, p. 31).

A reestruturação produtiva pode ser definida, em poucas palavras, como a transformação do modelo de acumulação taylorista-fordista no contexto do estado-nação, para a acumulação flexível no contexto da globalização (Nardi, 2006). Uma passagem da modernidade sólida, do capitalismo pesado, com imensas fábricas e milhares de trabalhadores, todos fixados no mesmo lugar, na qual Capital e Trabalho estavam ligados por uma relação de

\footnotetext{
2 Aqui estamos entendendo como liberalismo uma forma de organização social na qual o Estado evita interferir diretamente na relação Capital-Trabalho.

3 Não nos deteremos nos estudos sobre a mudança nas relações de trabalho nos países socialistas, pois nossa intenção é privilegiar a realidade brasileira.

4 Designação, à época, para os países africanos, sul-americanos, entre outros, que não se encaixavam nem no modelo capitalista nem no socialista.
} 
mútua dependência, para uma modernidade líquida, do capitalismo leve, que circula em um mundo globalizado, marcando o enfraquecimento dos laços que prendem Capital e Trabalho (Bauman, 2001). "A reprodução e o crescimento do capital, dos lucros e dos dividendos e a satisfação dos acionistas se tornaram independentes da duração de qualquer comprometimento local com o trabalho" (Bauman, 2001, p. 171). O compromisso do capital agora é, fundamentalmente, com o consumidor.

Enquanto o capital é global, no entanto, o trabalho continua local, com flexibilização e precarizacão dos contratos de trabalho, que não seguem mais o modelo do emprego da "sociedade salarial" (Castel, 1998). Ao contrário, caracterizam-se como contratos de curto prazo, sem garantias de continuidade, posições sem cobertura previdenciária, terceirizações de toda ordem, em um incremento do setor terciário (de serviços) em detrimento do setor produtivo. A vida no trabalho está saturada de incertezas, marcando a instauração do provisório como modo de existência (Castel, 1998). É preciso aprender a "surfar", "navegar", nessa fluidez típica dos líquidos que, diferente dos sólidos, "sofrem uma constante mudança de forma quando submetidos à pressão" (Bauman, 2001, p. 7), em uma passagem de uma mentalidade que fazia planos de longo prazo para uma mentalidade de curto prazo, que deve lidar com mudanças frequentes com rapidez.

Entende-se que o trabalhador não é apenas o executor de uma tarefa, mas ele deve incrementar seu trabalho com criatividade e responsabilizar-se pelos seus resultados; o que não é acompanhado, no entanto, pela oferta da mesma autonomia em relação à definição e à gestão do próprio trabalho. "Responsabilidades sem responsabilidade: eis aí uma das maiores dissociações do trabalho atual" (Clot, 2001, p. 4). A reestruturação produtiva, portanto, não é apenas incorporação de novas tecnologias, com o desenvolvimento e a conjugação das telecomunicações e da informática (terceira revolução industrial). Mais que isso, é uma mudança completa das formas de gestão e do valor moral atribuído ao trabalho (Nardi, 2006).

Para Castel (1998), configura-se uma nova questão social, que pode ser comparada, em amplitude e centralidade, com o pauperismo na primeira metade do século XIX. Ele identifica três pontos principais nessa nova configuração: a "desestabilização" dos estáveis; a instalação da precariedade, em uma alternância do emprego e do não-emprego; e um déficit de lugares, sobretudo para os adultos de meia idade - tarde demais para se reciclar, cedo demais para se aposentar - e os muito jovens, considerando que as qualificações exigidas são cada vez maiores. O trabalho, hoje, "exige a mobilização de competências não apenas técnicas, mas também sociais e culturais, que pegam no contrapé a cultura profissional tradicional de uma maioria de assalariados", considerando que "a formação permanente acaba funcionando como uma seleção permanente" (Castel, 1998, p. 519).

Qualificar-se, no entanto, não garante trabalho. Certamente a elevação do nível de formação dos trabalhadores é um importante objetivo social, mas isso não pode dissimular "um problema novo e grave: a possível não-empregabilidade dos qualificados" (Castel, 1998, p. 521). Pela importância que o conhecimento e o contínuo aprendizado adquiriram nesse contexto, alguns autores falam de um "capitalismo cognitivo" (Galvão, Silva \& Cocco, 2003) ou da predominância do "trabalho imaterial" (Gorz, 2005; Hardt \& Negri, 2005), discussões que neste momento não privilegiaremos.

\footnotetext{
5 Não confundir a oposição entre trabalho material e trabalho imaterial, ou entre trabalho prescrito e trabalho real, da ergonomia, com os conceitos de trabalho concreto e trabalho abstrato. Os trabalhos material e imaterial, embora não possam ser separados, estão relacionados ao que é mobilizado para a realização do trabalho e à visibilidade ou à invisibilidade daquilo que é produzido. Diz respeito ao que é privilegiado no processo de trabalho - o corpo ou a subjetividade do trabalhador ou, ainda, grosseiramente falando, é como que uma tentativa de distinguir o trabalho manual do intelectual. Já o trabalho prescrito e o trabalho real, como veremos de forma mais detalhada na segunda parte deste artigo, diz respeito ao hiato que se abre entre aquilo que deve ser feito, e o que realmente é realizado pelo trabalhador em sua atividade. Ambos os casos, portanto, só podem ser analisados em relação ao trabalho concreto, ao que acontece na realização cotidiana de cada atividade de trabalho, já que o trabalho abstrato é, como o nome diz, uma abstração, descolada da rotina singular de cada trabalhador.
} 
A função do Estado também sofre alterações importantes: se antes, como Estado de Bem-Estar Social, ele era "um esteio sem o qual nem capital, nem trabalho poderiam manter-se vivos e saudáveis, quanto mais crescer" (Bauman, 2001, p. 167), hoje o Estado passa das "políticas desenvolvidas em nome da integração para políticas conduzidas em nome da inserção" (Castel, 1998, p. 537). Castel conceitua as políticas de integração como aquelas que buscam um equilíbrio, uma homogeneização da sociedade a partir do centro, enquanto as políticas de inserção obedecem a uma lógica de "discriminação positiva", são medidas especificas para populações particulares, mais uma "ajuda" do que um "direito".

No Brasil, no entanto, não percebemos de forma tão marcante essas transformações no mundo do trabalho, na verdade, "mundos" do trabalho ${ }^{6}$. Aqui coexistem traços de um fordismo incompleto, da acumulação flexível, do trabalho clandestino, do trabalho ilegal e até mesmo do trabalho escravo (Antunes, 2000), somados ao fato de que, no sentido atribuído por Castel, nunca tivemos mecanismos eficientes de proteção ou de integração social.

Com a flexibilização e a precarizacão dos contratos de trabalho, muitos autores chegaram a apontar uma perda da centralidade do trabalho como categoria para pensar a sociedade (Gorz, 1987; Meda, 1999; Offe, 1994; Rifkin, 1996). No entanto, tantos outros (Antunes, 2005; Castel, 1998; Schwartz, 2007; Singer, 1998) demonstram que o que está em crise não é a centralidade do trabalho, mas a centralidade de uma das formas de trabalho, qual seja, a modalidade de emprego. "O trabalho continua sendo uma referência não só economicamente, mas também psicologicamente, culturalmente e simbolicamente dominante, como provam as reações dos que não o têm" (Castel, 1998, p. 578).

Em que pese sua diversidade, os autores apontam uma característica comum aos modos de trabalhar na atualidade, quando, para além da prescrição de uma tarefa específica, temos a prescrição da subjetividade (Clot, 2006). Em certo sentido, parafraseando Deleuze ${ }^{7}$, parece mais cruel do que a disciplinarização taylorista do corpo, o controle sutil e subjetivo do trabalhador. Devemos tomar cuidado, no entanto, com as avaliações apressadas e que pretendem unificar uma realidade sempre complexa.

Para Schwartz (2007), não podemos simplesmente julgar essas mudanças pelas quais passa o trabalho como boas - no sentido de que o trabalho se modernizou - nem ruins - na medida em que não foram conduzidas pelos trabalhadores - sem nos aproximarmos das situações concretas e reais de trabalho. Só assim poderemos "ver de perto como cada um não apenas 'se submete', mas vive e tenta recriar sua situação de trabalho" (p. 26). Ele concorda que não se pode falar em um "fim do trabalho", mas talvez no "declínio de certas formas clássicas do trabalho" (p. 26), considerando que "o trabalho foi sempre apreendido na mudança" (p. 25), embora existam períodos nos quais percebemos e sentimos de formas mais impactantes essas mudanças.

Assim, sem dúvida, temos uma transição em curso, na qual é importante perceber para além das limitações também as possibilidades de transformação e ampliação do poder de ação dos trabalhadores. Foi assim que Marx (Marx \& Engels, 1999/1848) percebeu uma das contradições do capitalismo nascente que, ao fazer equivaler diferentes tipos de trabalho e tentar administrar um grande número de trabalhadores no mesmo espaço de trabalho nas fábricas, não apenas alienou o trabalhador, mas também possibilitou a formação de um grupo homogêneo - a classe trabalhadora -, que, uma vez organizada, seria a mola propulsora da revolução. Da mesma forma, hoje poderíamos considerar a hipótese de que o capitalismo enfrenta um paradoxo, pois, por um lado, necessita de "um trabalhador competente, inovador, crítico, questionador, inteligente" e, por outro lado, essa demanda traz em si a possibilidade de questionamento e reinvenção do próprio sistema.

6 Termo cunhado por Eric Hobsbawm (1987).

7 No texto Post-Scriptum sobre as sociedades de controle (Deleuze, 1992). 
Na medida em que precisa de flexibilidade e plasticidade, o capitalismo pode estar sendo obrigado a ajudar na construção de formas de subjetivação que se tornem incompatíveis com sua própria manutenção, nos moldes como se encontra hoje. Quem garante que esta "plasticidade" não escape a seu controle? (Borges, 2006, p. 62).

Considerando essas questões, que nos ajudam a desnaturalizar a perspectiva um tanto generalista da sociologia sem, no entanto, desmerecer a importância de suas contribuições, concordamos com Schwartz quando diz que "todo discurso sobre o trabalho requer de nós uma extrema vigilância conceitual e dialética. Como saber se o trabalho muda (...) sem um olhar filosófico sobre o próprio conceito?" (Schwartz, 2000, apud Borges, 2006, p. 70). É a esse convite que cedemos agora, buscando amparo na filosofia para ampliar nosso entendimento sobre as configurações do trabalho na atualidade.

\section{Filosofia: o trabalho como objeto ou matéria estrangeira?}

Yves Schwartz $(2003)^{8}$ pergunta-se como a filosofia, "como patrimônio de escritos e como atividade intelectual" (p. 1), pode contribuir para entender e transformar o trabalho hoje. Tal como Canguilhem em relação à medicina, Schwartz defende que o trabalho não seja apenas um objeto de estudo para a filosofia, mas "matéria estrangeira", que convide o filósofo a se colocar em uma posição de humildade e aprendizado frente aos mundos do trabalho. Sendo assim, ele se propõe a analisar os estudos filosóficos sobre o trabalho ${ }^{9}$, destacando justamente aqueles em que o trabalho é tratado como matéria estrangeira, mesmo que de forma transversal.

É o caso da tradição da filosofia clássica, na qual o trabalho foi modestamente tratado como matéria estrangeira. O exemplo citado por Schwartz é o texto Apologia de Sócrates, no qual Platão (1965) descreve a defesa de Sócrates perante seus acusadores. Sócrates relata que um dia, estando em Delfos, seu amigo Xenofontes pergunta ao oráculo se existe alguém mais sábio do que Sócrates, ao que o oráculo responde que não: Sócrates é o mais sábio. Intrigado, Sócrates começa a procurar alguém que possa ser mais sábio que ele. A primeira figura com quem ele compara sua sabedoria é a do político, concluindo que "(...) aquele homem acredita saber alguma coisa, sem sabê-la, enquanto eu, como não sei nada, também estou certo de não saber. Parece, pois, que eu seja mais sábio do que ele nisso - ainda que seja pouca coisa: não acredito saber aquilo que não sei” (p. 36). Em seguida, ele visita os poetas, mas se decepciona ao perceber que não faziam poesia por sabedoria, mas por intuição e inclinação, e "embora digam muitas e belas coisas, não sabem nada daquilo que dizem" (p. 38). Finalmente, Sócrates vai até os artífices, convencido de que eles nada sabiam, mas confessa: "(...) nisso me enganei: eles, de fato, sabiam aquilo que eu não sabia e eram muito mais sábios do que eu” (p. 39). No entanto, ao mesmo tempo em que Sócrates demonstra interesse por essa sabedoria, considera que os artesãos desconhecem os limites de seu saber, já que sua arte é secundária em relação a outros saberes, essenciais à boa conduta.

É um reconhecimento modesto da atividade de trabalho como matéria estrangeira, ainda limitada ao mundo artesanal. Esses limites permanecem nas análises de outros grandes filósofos clássicos, como Leibniz e Descartes, embora a ênfase seja outra. Para eles, o saber laborioso passa a ter sua importância não por poder contribuir para um governo dos homens pela Virtude e pelo Bem, mas pela possibilidade de contribuir com a dominação da natureza

8 Trata-se de uma conferência proferida por Schwartz em um Seminário sobre Educação e Trabalho, em Cuiabá (MT), em 2003, recentemente publicada (Schwartz, 2008). No entanto, aqui nos valemos da tradução do Prof ${ }^{\mathrm{a}}$. Marie-Anik Bernier, anterior a sua publicação (disponível em http://www.esnips.com/doc).

9 Ou atividade laboriosa, ligada às atividades artesanais, já que o conceito de trabalho, em sua forma genérica e generalizável, como já vimos, nasce a partir da revolução industrial, na modernidade. 
pela ciência. Segundo Schwartz (2003), Descartes, em seu Discurso do método, interessa-se pela maneira com que os artesãos valem-se das leis naturais em suas atividades, embora não as conheçam. Ele refere-se à relação respeitosa que se estabeleceu entre Descartes e seu cortador de lentes favorito, Ferrier. O filósofo, em uma série de cartas que troca com o amigo, observa que "é preciso reconhecer que acontecem mil encontros no decorrer do trabalho que não se podem prever no papel" (Descartes, 1999, apud Schwartz, 2003, p. 4), e lidar com essa imprevisibilidade faz parte do saber do artesão, mesmo que ele não saiba explicá-la.

Assim, a atividade dos homens de profissão é matéria estrangeira para o filósofo, algo que ele não domina, porém, que precisa conhecer, "não somente para construir seus instrumentos científicos, mas também para fazer avançar seus grandes desígnios", já que, ao contrário do artesão, o filósofo pode "antecipar as causas por meio dos efeitos" e, assim, potencializar a intervenção humana sobre a natureza (Schwartz, 2003, p. 4). No entanto, tal como em Platão, o reconhecimento cartesiano do trabalho como matéria estrangeira não quebra a hierarquia entre os saberes, pois o saber do artesão é considerado limitado à sua especialidade, ao passo que o saber do filósofo, baseado no método intelectual, seria universal.

Leibniz, seguindo os passos de Descartes, também procura inventariar os "conhecimentos adquiridos graças à experiência", igualmente apontando sua importância e sua limitação, afirmando preferir o "homem hábil" a um "meio cientista" (Leibniz, 1967, apud Schwartz, 2003, p. 5). Finalmente, Diderot, na aurora da revolução industrial, de forma mais contundente que Descartes ou Leibniz, ressalta a importância de aprender com os "homens de profissão", bem como a "necessária humildade do filósofo em relação ao gênio artesanal". Diz ele em sua Enciclopédia (1965, apud Schwartz, 2003): "Há em toda arte um grande número de circunstâncias relativas à matéria, aos instrumentos e à manobra, que somente o uso ensina" (p. 5). No entanto, em que pese esse explícito reconhecimento, permanece a mesma crítica à limitação do saber daqueles que "exercem as artes mecânicas", mais por necessidade que por vocação, operando instintivamente e sem conseguir, muitas vezes, expressar-se sobre aquilo que fabricam.

Sendo assim, conclui Schwartz, nessa filiação da filosofia clássica, o trabalho não é tratado apenas como objeto, mas, mesmo que timidamente, também como matéria estrangeira, na medida em que dá acesso a "problemas humanos concretos" que não podem ser acessados unicamente pelas teorias intelectuais. Existe o reconhecimento do saber do trabalhador, embora seja considerado um "saber menor" em relação à filosofia.

Schwartz não inclui Aristóteles nessa genealogia, pois entende que esse filósofo, ao tentar classificar e dividir as atividades humanas em categorias distintas, deu origem a uma tradição filosófica na qual o trabalho desaparece como problema, transformando-se em mero objeto de estudo, subordinado intelectual e moralmente ao saber filosófico. Aristóteles dividiu o campo das atividades humanas entre as coisas que se fabricam (poiésis) e os atos que se cumprem (práxis), marcando a separação entre a ação, como a dimensão mais nobre da experiência humana, e o trabalho, como atividade penosa e imposta.

A práxis, explica Schwartz (2003), supõe o exercício da razão, orientada pela virtude, envolve escolhas e arbitragens entre valores e, por isso, essa tradição filosófica, inaugurada por Aristóteles, é também chamada de "filosofia moral". Já a atividade de trabalho, nessa perspectiva, parece não levantar nenhuma questão, nenhum conflito moral que exija o discernimento da razão, sendo mera execução de técnicas já conhecidas. Os herdeiros contemporâneos dessa tradição seriam, para Schwartz, Habermas e Hannah Arendt, que influenciaram decisivamente autores que ganharam destaque na atualidade, a partir da discussão do "fim da sociedade (da centralidade) do trabalho", tais como Gorz (1987), Offe (1994), Rifkin (1996) e Meda (1999). 
Habermas (2000) aponta que a modernidade, mesmo que dominada por uma racionalidade instrumental e tecnicizada, criou condições para reativar a práxis aristotélica. Para ele, ampliou-se a separação entre aquilo que chamou de "mundo da vida" - esfera da razão comunicativa, da intersubjetividade, na qual a integração social advém pela adesão a normas comuns, fruto do consenso e da comunicação entre os sujeitos - e o "sistema" - esfera da economia, da política e da razão instrumental, na qual a integração sistêmica "é obtida por uma regulamentação não normativa das decisões individuais, que vai além da consciência dos atores" (Habermas, 1997, apud Gorz, 2003, p. 40).

Com a complexificação da sociedade moderna, Habermas (2000) identifica um processo que denominou "colonização do mundo da vida", no qual o poder e o dinheiro (e o trabalho!) ligados ao sistema "invadiram" e se sobrepuseram à esfera interativa e comunicativa do mundo da vida. Sendo assim, a utopia da emancipação dos sujeitos estaria na ampliação dos espaços de ação no mundo da vida, no qual a comunicação cumpre papel privilegiado, e não na transformação do trabalho ou na passagem do trabalho alienado para o trabalho autodirigido, como entendia Marx (Antunes, 2000). Justifica-se, assim, a denominação "teoria do agir comunicacional", escolhida por Habermas para identificar essa práxis, no sentido forte do termo, como "a reivindicação de um espaço público, lutando contra sua colonização pela economia e o poder" (Schwartz, 2003, p. 8).

Podemos perceber, assim, que, seguindo a tradição aristotélica, Habermas nos apresenta uma visão sistêmica e binária da sociedade, considerando o trabalho como parte do "sistema", separado e até mesmo antagônico ao "mundo da vida". O pensamento habermasiano nos passa essa ideia de uma necessária "libertação" das pesadas amarras do sistema (e do trabalho), sendo preciso resgatar a força do mundo da vida, de um espaço público, que também parece já ter existido, e depois diminuído, na medida em que foi "colonizado" pelo sistema.

Em Hannah Arendt essa limitação fica ainda mais evidente, na medida em que ela refere-se direta e constantemente à filosofia grega e, especificamente, a Aristóteles. É conhecida a divisão que realiza entre as três atividades humanas fundamentais: labor, trabalho e ação. O labor estaria relacionado às necessidades vitais e biológicas do corpo humano, garantindo a sobrevivência não só do indivíduo, mas também da espécie. $O$ trabalho corresponderia ao artificialismo da existência humana, àquilo que é produzido e está fora de qualquer ambiente natural, emprestando "certa permanência e durabilidade à futilidade da vida mortal e ao caráter efêmero do tempo humano" (Arendt, 1995, p. 16). Finalmente, a ação diz respeito à relação entre os homens, aos corpos políticos e à pluralidade. Enquanto o labor produz os bens de consumo que asseguram a sobrevivência e o trabalho origina os objetos de uso, os produtos da ação "constituem a textura das relações e dos negócios humanos" (p. 106).

Arendt segue a definição aristotélica do homem como ser cuja verdade se expressa como "ação" no seio de um espaço público, no qual acontecem os debates sobre a melhor forma de conduzir a cidade. Para Aristóteles, nem o labor - reservado ao escravo - nem o trabalho ${ }^{10}-$ função dos artesãos livres e mercadores - poderiam constituir um modo de vida autônomo, pois "não podiam ser livres e independentes das necessidades e privações humanas" (p. 21).

Ela critica Marx na medida em que ele compreendia que o trabalho - e não a razão distinguia os homens dos outros animais, alertando que sua teoria "era apenas a formulação mais radical e coerente de algo com que toda era moderna concordava" (p. 97). Considera,

\footnotetext{
10 Arendt (1995, p. 90) afirma que a distinção que realiza entre labor e trabalho parece inusitada - algo que poderia ser resumido como o "labor do nosso corpo e o trabalho de nossas mãos", na medida em que não existem provas históricas documentadas que possam comprová-la. No entanto "há uma testemunha muito eloquente e obstinada: a simples circunstância de que todas as línguas europeias, antigas e modernas, possuem duas palavras de etimologia diferente para designar o que para nós, hoje, é a mesma atividade, e conservam ambas a despeito do fato de serem repetidamente usadas como sinônimas". Em grego: ponein e ergazesthai; em latim: laborare e fabricari; em francês: travailler e ouvrer; em alemão: arbeit e werk; em inglês: labor e work. Em todos eles, só os equivalentes à labor têm conotação de dor ou atribulação, enquanto os substantivos "work", "ouvre” e "werk" (ou "obra” em português) tendem a ser relacionados a obras de arte.
} 
ainda, que Marx foi contraditório em relação ao próprio foco de seu pensamento, pois, embora tratasse o trabalho como a mais humana e produtiva das atividades humanas, a revolução, por ele defendida, "não se destinava a emancipar as classes trabalhadoras, mas emancipar o homem do trabalho", ou seja, somente quando o trabalho imposto fosse abolido, seria possível que o reino da liberdade suplantasse o reino da necessidade (Arendt, 1995, p. 116).

Nesse sentido, Schwartz (2003) chama atenção para o fato de que, apesar de pertencerem à mesma matriz filosófica, nem Habermas nem Arendt limitam-se à herança aristotélica, estabelecendo um diálogo crítico com o marxismo: "Eles censuram o marxismo, não por ter feito do trabalho um objeto - eles também o fazem, mais ou menos -, mas um objeto privilegiado, em detrimento de uma definição da ação" (p. 10), que ambos reconstroem. Essa tendência é seguida por outros autores contemporâneos (Gorz, 1987, 2003; Meda, 1999; Offe, 1994; Rifkin, 1996), que vislumbram uma crise da sociedade fundada no trabalho, a radical e crescente separação entre o trabalho e a vida, e a necessidade de que outras atividades geralmente também relacionadas à política e à ocupação do espaço público - tomem "o lugar" do trabalho como fonte de pertencimento social e desenvolvimento pessoal.

Já no marxismo, a presença do trabalho como conceito geral e abstrato sem dúvida é um objeto privilegiado, mas talvez não como matéria estrangeira. Schwartz (2003, p. 11) questiona, por exemplo, se, ao organizar a história em torno do trabalho, Marx não acabou privilegiando o nível macroscópico, desconsiderando o ponto de vista dos trabalhadores e o aprendizado de como eles "criam história, não no abstrato, mas através de múltiplas situações locais, concretas, singulares" ${ }^{11}$. Seguindo esse raciocínio, Schwartz acredita que o maior problema talvez esteja na diferenciação marxiana entre trabalho concreto e trabalho abstrato.

O trabalho concreto está relacionado com o valor de uso das mercadorias, no qual "cultivar o trigo" não é o mesmo que "tecer a seda", pois trigo e seda são qualitativamente diferentes, envolvem atividades de trabalho totalmente distintas e têm utilidades igualmente diferentes. Já o trabalho abstrato diz respeito ao valor de troca, aquilo que iguala todas as mercadorias, em função de quanto valem para a troca, independentemente das práticas concretas necessárias para produzi-las. É assim que o trabalho humano pode ser comprado, como uma mercadoria, na medida em que pode ser generalizado, independentemente de sua forma particular, como um quantum (Marx, 1996). E essa foi, para Schwartz (2003), a grande descoberta de Marx, que pôde ver a equivalência que se escondia sob a diferença visível e manifesta entre o trabalho do tecelão e o do lavrador. No entanto:

(...) como evitar que este apelo tão fecundo para a indiferença não tenha também seu reverso negativo: se a verdade do trabalho nas relações de produção capitalistas é a sua existência como quantum de trabalho abstrato, é a indiferença a suas formas concretas, por que o filósofo, mas também o militante, o revolucionário, iriam juntos aos trabalhadores concretos se interrogar sobre o que se passa nas cabeças deles? (Schwartz, 2003, p. 13).

É assim que Schwartz estabelece uma relação entre o trabalho abstrato - conceito genérico que se torna o objeto privilegiado da reflexão política, filosófica e cultural (como, inclusive, pudemos perceber na primeira parte deste capítulo) - e o trabalho concreto, matéria estrangeira, relegado a um segundo plano, seja na filosofia, nos estudos da área do trabalho, seja até mesmo nas reivindicações sindicais.

Nesse sentido, Schwartz retoma o trabalho de Ivar Oddone, médico italiano que colocou a experiência operária no centro das análises da relação entre saúde e trabalho, que percebia "uma estranha compatibilidade" entre dois autores antagônicos: Marx e Taylor. Ele argumenta que um ponto em comum entre os dois é a ausência de um "modelo positivo de

11 próprio Schwartz destaca, no entanto, as frequentes referências de Marx aos relatórios dos inspetores de fábricas, que demonstram que ele se instruía, diretamente, do que chamou de "laboratório secreto da produção" (Marx, apud Schwartz, 2003, p. 12). 
trabalhador", "capaz de refletir sobre sua condição de explorado e de alienado, e de produzir respostas (...)" (Oddone, 1981, apud Schwartz, 2003, pp. 14-15). O trabalho concreto em Marx parece coincidir, de alguma maneira, com o trabalho que pode ser totalmente planejado "cientificamente", como propõe Taylor. É um trabalho heterodeterminado, subordinado, normatizado, no qual "as microcriações laboriosas, as transgressões, as reservas de alternativas que Oddone tinha tão notavelmente revelado em andamento na experiência operária, e simultaneamente os ergônomos da atividade na França", são praticamente ignoradas (Schwartz, 2003, p. 15).

Schwartz (2003) concorda que é necessário que o trabalho seja reconhecido como objeto, tal como o faz a sociologia, por exemplo. É importante contextualizar o movimento histórico, político e social. No entanto, tal preocupação não pode encobrir que o trabalho é uma forma de atividade humana que nos introduz a problemas humanos e filosóficos, chamando à construção saberes específicos que devem ancorar-se nas experiências daqueles que vivenciam as situações de trabalho. Mesmo naquelas atividades de trabalho mais automatizadas e controladas, sempre há um espaço, mesmo que pequeno e aparentemente insignificante, no qual é o trabalhador quem se coloca, com seus valores e crenças. Ao identificar essa dinâmica incessante de negociação presente na atividade de trabalho, não podemos mais pensá-lo apenas como objeto, mero produtor de valor ou alienação. É preciso interrogá-lo como "matéria estrangeira", que só pode ser apreendida nas relações microscópicas e concretas do cotidiano.

\section{À guisa de conclusão}

Consideramos que as contribuições de Yves Schwartz podem nos auxiliar a avançar no processo de mudança do paradigma sanitário brasileiro, do qual faz parte o campo da Saúde do Trabalhador. Este se constituiu como contraponto à hegemonia da Medicina do Trabalho, com a proposta de deslocar o centro da análise da relação entre saúde e trabalho, do indivíduo para o processo de trabalho. Sobretudo, defende o protagonismo dos trabalhadores na identificação e no enfrentamento de situações produtoras de adoecimento, incentivando a incorporação de suas experiências cotidianas na produção científica sobre o tema, entendendo-o como sujeito ativo do processo saúde-doença e não, simplesmente, como objeto de atenção à saúde (Minayo-Gomez \& Thedim-Costa, 1997).

Cabe-nos perguntar, como técnicos, especialistas, pesquisadores ou militantes da Saúde do Trabalhador, que estratégias colocamos em curso para aguçar esse olhar microscópico sobre o trabalho concreto, as (micro) gestões e invenções dos trabalhadores? Que lugar ocupam o protagonismo e o saber dos trabalhadores nessas estratégias? Parecem perguntas simples, mas concordamos com Brito e Athayde (2003), quando destacam que a compreensão da importância do saber do trabalhador não é suficiente "para eliminar um obstáculo epistemológico que se aprende e "imprende" ao longo da formação como universitário: a pretensão e a arrogância, esta forma de ignorância impermeável” (p. 84).

É nesse sentido que Schwartz (2000) vai apontar a necessidade de uma "humildade epistemológica" para potencializar o encontro entre o "polo dos saberes organizados" (das disciplinas, dos "especialismos') e o "polo dos saberes investidos na atividade" (da experiência cotidiana dos trabalhadores). Uma troca que exige humildade de ambos os lados: dos pesquisadores e especialistas, para retornar a palavra aos trabalhadores, e dos trabalhadores, para aprender e debater os conceitos. E não apenas isso: talvez nosso maior desafio não seja apenas incorporar as experiências dos trabalhadores aos estudos acadêmicos, mas auxiliar no 
desenvolvimento e fortalecimento dessas experiências, visando à ampliação da capacidade de fomento e defesa da saúde dos trabalhadores.

\section{Referências}

Antunes, R. (2000). Os sentidos do trabalho: ensaio sobre a afirmação e negação do trabalho. São Paulo: Boitempo.

Antunes, R. (2005). Adeus ao trabalho? Ensaio sobre as metamorfoses e a centralidade do mundo do trabalho. São Paulo: Cortez.

Arendt, H. (1995). A condição humana. Rio de Janeiro: Forense Universitária.

Baumann, Z. (2001). Modernidade líquida. Rio de Janeiro: Zahar.

Borges, M. E. S. (2006). O RH está nu: tramas e urdiduras por uma gestão coletiva do trabalho. Tese de Doutorado, Programa de Pós-Graduação em Psicologia Social, Universidade Estadual do Rio de Janeiro, Rio de Janeiro.

Brito, J. \& Athayde, M. (2003). Trabalho, educação e saúde: o ponto de vista enigmático da atividade. Revista Trabalho, Educação e Saúde, 1 (2), 239-265.

Castel, R. (1998). As metamorfoses da questão social: uma crônica do salário. Petrópolis, RJ: Vozes.

Deleuze, G. (1992). Conversações: 1972-1990. Rio de Janeiro: Editora 34.

Descartes (1999). Discurso do Método. São Paulo: Martins Fontes.

Diderot (1965). Prospectus de l'Encyclopédie. Paris: Gonthier.

Galvão, A., Silva, G. \& Cocco, G. (2003). Capitalismo cognitivo: trabalho, redes e inovação. Rio de Janeiro: DP\&A.

Gorz, A. (1987). Adeus ao proletariado. São Paulo: Forense Universitária.

Gorz, A. (2003). Metamorfoses do trabalho: crítica da razão econômica. São Paulo: Annablume.

Gorz, A. (2005). O imaterial: conhecimento, valor e capital. São Paulo: Annablume.

Habermas (1997). Theorie des kommunikativen Handelns- Band 2- Zur Kritik der funktionalistischen Vernunft 2. Frankfurt am Main: Suhrkamp.

Habermas, J. (2000). O discurso filosófico da modernidade. Portugal: Publicações Dom Quixote.

Hardt, M. \& Negri, A. (2005). Multidão. Rio de Janeiro: Record.

Hobsbawm, E. (1987). Mundos do trabalho. Rio de Janeiro: Paz e Terra.

Marx, K. \& Engels, F. (1999). Manifesto do Partido Comunista. São Paulo: Paz e Terra.

Marx, K. (1996). A mercadoria. In K. Marx O Capital (cap. 1). São Paulo: Nova Cultural.

Meda, D. (1999). O trabalho: um valor em vias de extinção. Lisboa: Fim de Século.

Minayo-Gomez, C. \& Thedim-Costa, S. M. F. (1997). A construção do campo da saúde do trabalhador: percurso e dilemas. Cadernos de Saúde Pública, 13 (supl. 2), 21-32.

Nardi, H. C. (2006). Ética, trabalho e subjetividade: trajetórias de vida no contexto das transformações do capitalismo contemporâneo. Porto Alegre: UFRGS.

Oddone, Y. (1981) Redécouvrir l'expérience ouvrière. Paris: Editions Sociales.

Oddone, I. (1986). Ambiente de trabalho: a luta dos trabalhadores pela saúde. São Paulo: Hucitec.

Offe, C. (1994). Capitalismo desorganizado: transformações contemporâneas do trabalho e da política. São Paulo: Brasiliense.

Platão. (1965). Apologia de Sócrates. Rio de Janeiro: Edições de Ouro.

Rifkin, J. (1996). O Fim dos empregos. São Paulo: Makron.

Schwartz, Y. (2000). Trabalho e uso de si. Proposições, 11 (2), 34-50.

Schwartz, Y. (2000). Le travail change-t-il vraiment? in Le Paradigme Ergologique ou un Métier de Philosophe. Toulouse: Octarès. 
Schwartz, Y. (2003). O trabalho numa perspectiva filosófica. Seminário Trabalho, Saber, Educação. Cuiabá. [Comunicação oral, digitado]

Schwartz, Y. (2007). Trabalho e ergologia. In Y. Schwartz \& L. Durrive (Orgs.), Trabalho e ergologia: conversas sobre a atividade humana. Niterói, RJ: EdUFF.

Schwartz, Y. (2008). O trabalho numa perspectiva filosófica. in I. Nozaki (Org.), Educação e Trabalho: trabalhar, aprender, saber. Campinas: Mercado de Letras. Cuiabá: Editora da UFMT.

Singer, P. (1998). Uma utopia militante: repensando o socialismo. Petrópolis, RJ: Vozes.

Weber, M. (2004/1904). A ética protestante e o espírito do capitalismo. São Paulo: Martin Claret.

\section{Endereço para correspondência}

tatiana@ramminger.com.br

Recebido em: 06/02/2009

Revisado em: 22/03/2010

Aprovado em: 25/03/2010 